\title{
AS RELAÇÕES ENTRE VALOR AGREGADO E RIQUEZA NA ANÁLISE- DIAGNÓSTICO DE SISTEMAS AGRÁRIOS
}

Benedito Silva Neto ${ }^{1}$

\begin{abstract}
RESUMO
A Análise-Diagnóstico de Sistemas Agrários (ADSA) é um método de estudo empregado na extensão rural e em pesquisas sobre dinâmicas locais da agricultura. Neste método normalmente é considerado que a agregação de valor é equivalente à geração de riqueza. O objetivo deste artigo é analisar os problemas provocados pela consideração do valor agregado como um indicador da produção de riquezas na ADSA. Uma demonstração formal de que valor agregado e riqueza são distintos é realizada a partir de um modelo de programação linear, com base no materialismo histórico. Esta demonstração é ilustrada por um exemplo numérico e, após, as relações entre valor agregado e riqueza são discutidas a partir da análise de alguns trabalhos que empregam a ADSA. Conclui-se que uma adoção generalizada de sistemas de produção com alta capacidade de agregação de valor, como em geral proposto a partir da ADSA, pode implicar em uma diminuição da produção de riquezas. No entanto, a crítica a este aspecto da ADSA não implica em subestimar a grande relevância deste método de análise regional da agricultura.
\end{abstract}

Palavras-chave: cálculo econômico, extensão rural, sustentabilidade, teoria do valor.

\section{THE RELATIONS BETWEEN ADDED VALUE AND WEALTH IN THE ANALYSIS- DIAGNOSIS OF AGRARIAN SYSTEMS}

\begin{abstract}
The Analysis-Diagnosis of Agrarian Systems (ADSA) is a method used in rural extension and in research on local dynamics of agriculture. In this method, it is normally considered that adding value is equivalent to generating wealth. The article aims to analyze the problems caused by considering added value as an indicator of the production of wealth in ADSA. A formal demonstration that added value and wealth are distinct is carried out using a linear programming model, based on historical materialism. This demonstration is illustrated by a numerical example and, afterwards, the relations between added value and wealth are discussed based on the analysis of some works that use ADSA. It is concluded that a widespread adoption of production systems with a high capacity to add value, as generally proposed from the ADSA, may imply a decrease in the production of wealth. However, criticism of this aspect of ADSA does not imply underestimating the great relevance of this method of regional analysis of agriculture.
\end{abstract}

Keyword: economic calculation, rural extension, sustainability, value theory.

\footnotetext{
${ }^{1}$ Graduado em Agronomia (UNESP/Jaboticabal). Mestrado em Biodinâmica e Produtividade do Solo (UFSM). Doutorado em Desenvolvimento Agrícola (INA-PG/França). Professor do PPG em Desenvolvimento e Políticas Públicas (PPGDPP) da Universidade Federal da Fronteira Sul (UFFS). E-mail: bsilva@uffs.edu.br
} 


\section{INTRODUÇÃO}

Elaborada no quadro de uma teoria da evolução histórica e diferenciação geográfica da agricultura em nível mundial (MAZOYER; ROUDART, 1997), a AnáliseDiagnóstico de Sistemas Agrários (ADSA) há décadas tem sido aplicada para a formulação de linhas estratégicas de desenvolvimento da agricultura em nível local e regional. Mais recentemente, tem-se verificado em muitos desses trabalhos uma forte vinculação da ADSA com a promoção da Agroecologia ou outros tipos de agricultura alternativa (DEVIENNE et. al., 2017; GARAMBOIS e DEVIENNE, 2013; SILVA NETO, 2014). Além disso, análises econômicas baseadas nos princípios metodológicos e procedimentos propostos na ADSA têm sido realizadas em estudos do desenvolvimento industrial em nível local (BASSO e MÜENCHEN, 2006; STOFFEL, 2004).

Uma importante característica dos trabalhos de pesquisa e extensão realizados por meio da ADSA é a adoção do valor agregado para a realização de análises econômicas (DUFUMIER, 1996). Além disto, as propostas de desenvolvimento formuladas no âmbito desses trabalhos são fortemente influenciadas pela identificação do valor agregado com a produção de riquezas, privilegiando em suas recomendações atividades que agregam mais valor. Garambois e Devienne (2013) chegam mesmo a considerar que a promoção de atividades que geram mais valor agregado por meio do emprego de mais força de trabalho e menor quantidade de meios de produção, com uma suposta maior produção de riquezas, representa uma verdadeira mudança de paradigma. Assim, a identificação do valor agregado com a geração de riquezas, aliada à Agroecologia, poderia servir de base para uma maior produção de riquezas, assim como para a promoção da sustentabilidade ecológica e a justiça social.

O objetivo deste artigo é analisar os problemas provocados pela consideração do valor agregado como um indicador da produção de riquezas na ADSA. Além desta introdução e das conclusões, este artigo é composto por três seções. Na primeira é realizada uma demonstração de que a equação normalmente adotada para o cálculo do valor agregado em unidades de produção pode ser deduzida formalmente a partir de relações macroeconômicas entre riquezas, valores e preços concebidas no quadro do materialismo histórico, tal como proposto por Silva Neto (2020a). Nesta demonstração, é evidenciado que o valor agregado é apenas um equivalente monetário do tempo de trabalho socialmente necessário à produção, cuja magnitude é inversamente proporcional a quantidade de riqueza gerada por unidade de tempo de trabalho. Na segunda seção, os resultados obtidos na primeira seção são ilustrados por meio de um exemplo numérico. Na terceira seção é realizada uma discussão dos problemas provocados pela confusão entre valor agregado e riqueza na ADSA.

\section{AS RELAÇÕES ENTRE RIQUEZAS, VALORES E PREÇOS E O CÁLCULO DO VALOR AGREGADO}

No âmbito do materialismo histórico, a distinção entre valor agregado e riqueza é largamente reconhecida. Em trabalhos recentes, tal distinção tem sido enfatizada em função da sua importância para a fundamentação de uma crítica "socioecológica" da economia capitalista (HARRIBEY, 2013, 2015). Nesta perspectiva, o valor de uso de um produto, que pode ser denominado simplesmente de riqueza, é considerado distinto do valor de troca (ou simplesmente valor), sendo este último baseado no trabalho socialmente necessário a produção, a partir do qual são determinados os preços. Assim, as riquezas possuem um caráter qualitativo que 
as tornam incomensuráveis entre si, enquanto valores e preços possuem um caráter quantitativo (HARRIBEY, 2011).

A partir dessas concepções as relações entre produtividade do trabalho, valores e preços podem ser analisadas considerando a produtividade do trabalho como,

$$
p_{w}=\frac{Q}{T}
$$

Onde,

$\mathrm{p}_{\mathrm{w}}=$ produtividade do trabalho

$\mathrm{Q}=$ quantidade produzida

$\mathrm{T}=$ valor em tempo de trabalho

Sendo o preço, aproximadamente, definido por,

$$
p_{c} \approx \frac{T}{Q}
$$

Onde, além das variáveis já definidas, $\mathrm{p}_{\varsigma}=$ preço

As relações descritas acima implicam que o preço é inversamente proporcional à produtividade, ou seja,

$$
p_{c} \approx \frac{1}{p_{t}}
$$

Assim, o aumento da produtividade do trabalho, socialmente, implica na diminuição dos preços, ou seja, o preço é uma variável dependente inversamente proporcional à produtividade. Neste caso, se o valor em tempo de trabalho (T) permanece constante, um aumento da produção $(\mathrm{Q})$, ou seja, da riqueza, não implica em aumento da geração de valor monetário, na medida em que provoca a queda do preço. Vale salientar, no entanto, que as relações enunciadas anteriormente são apenas aproximadas, na medida em que o preço, salvo em condições muito específicas, não corresponde ao valor médio, mesmo na ausência do processo de equalização as taxas de lucro (SILVA NETO, 2020a, p. 152).

No entanto, as relações descritas anteriormente não se aplicam imediatamente em uma unidade de produção tomada isoladamente. Como o efeito de uma variação da produtividade de uma unidade de produção sobre a produtividade do conjunto da economia (e, portanto, sobre o preço) em geral é muito baixo (especialmente na agricultura), em uma unidade de produção não há uma relação imediata entre preço e produtividade. Isso aparentemente torna o valor agregado nas unidades de produção uma variável dependente da produtividade, o que pode ser demonstrado a partir da expressão empregada na ADSA para o cálculo do valor agregado, descrita em Dufumier (1996, p. 95) como,

$$
V A=P B-C I-D
$$

Onde,

$\mathrm{VA}=$ valor agregado

$\mathrm{PB}=$ produção bruta (valor total da produção)

$\mathrm{Cl}=$ consumo intermediário (valor dos meios de produção consumidos no ciclo de produção)

$D=$ depreciações (valor da fração dos meios de produção que são consumidos em vários ciclos de produção)

Considerando que, 


$$
P B=Q p_{\zeta}
$$

Obtém-se,

$$
V A=Q p_{C}-C l-D
$$

A expressão (6) implica que um aumento da produção (Q) sem uma diminuição do preço $\left(p_{c}\right)$ provoca um aumento do valor agregado (VA). Mas, como já mencionado, isto só ocorre ao nível microeconômico na medida em que os preços $\left(p_{c}\right)$ se modificam com a alteração das condições de produção no conjunto da economia. Isto implica na necessidade de elucidar as relações entre valor agregado e riqueza que ocorrem ao nível macroeconômico e, a partir dessas relações, como pode ser deduzida a equação empregada para o cálculo do valor agregado nas unidades de produção.

Tal demonstração tem como ponto de partida a concepção marxista de que o acesso às riquezas sociais é, sobretudo, um produto da luta de classes e não o resultado de um processo propriamente econômico, como Marx expressa em relação à demanda na seguinte afirmação,

\begin{abstract}
Observemos aqui, apenas de passagem, que as "necessidades sociais", isto é, aquilo que regula o princípio da demanda, encontram-se essencialmente condicionadas pela relação das diversas classes entre si e por sua respectiva posição econômica, ou seja, em primeiro lugar, pela proporção entre o mais-valor total e o salário; em segundo lugar, pela proporção entre as diversas partes nas quais se decompõe o mais-valor (lucro, juros, renda fundiária, impostos, etc.). De modo que aqui novamente se demonstra que não se pode explicar absolutamente nada a partir da relação entre a oferta e a demanda, antes de estar desenvolvida a base sobre a qual opera esta relação. (MARX, 2017, p. 216).
\end{abstract}

De acordo com o materialismo histórico, assim, o acesso às riquezas no capitalismo é determinado por processos sociais objetivos fundados na luta de classes. Portanto, definida certa quantidade demandada, a oferta é determinada pelas condições em que ocorrem os processos de trabalho, cuja natureza é esclarecida por Marx quando ele diz que,

Os valores de uso casaco, linho etc., em suma, os corpos das mercadorias, são nexos de dois elementos: matéria natural e trabalho. Subtraindo-se a soma total de todos os diferentes trabalhos úteis contidos no casaco, linho etc., o que resta é um substrato material que existe na natureza sem a interferência da atividade humana. Ao produzir, o homem pode apenas proceder como a própria natureza, isto é, pode apenas alterar a forma das matérias. Mais ainda: nesse próprio trabalho de formação ele é constantemente amparado pelas forças da natureza. Portanto, o trabalho não é a única fonte dos valores de uso que ele produz, a única fonte da riqueza material. (MARX, 2011, p. 167)

Esta citação mostra a precisa concepção de Marx do processo de trabalho. Nela Marx deixa claro que o trabalho se constitui, essencialmente, na forma específica como os seres humanos se relacionam com a natureza para obter os produtos que necessitam. Os recursos naturais ocupam, portanto, uma posição central na concepção de Marx do trabalho. Por outro lado, é importante salientar que, no 
materialismo histórico, o trabalho é sempre concebido como uma atividade realizada a partir de relações sociais. Em suma, pode-se inferir a partir da concepção exposta por Marx que o trabalho se constitui em uma relação dos seres humanos com a natureza, mediada por relações dos seres humanos entre si. Enfim, ao mesmo tempo em que o trabalho possui um caráter ontológico fundante do ser humano (LUKÁCS, 2013), ele possui também um caráter histórico, na medida em que as relações sociais se alteram ao longo do tempo, notadamente em consonância com o avanço das forças produtivas representadas pelo domínio que os seres humanos exercem sobre os processos naturais, a partir dos quais ocorre o trabalho.

O trabalho, portanto, ocupa um lugar central na concepção histórica e materialista da realidade inaugurada por Marx e Engels. É, portanto, compreensível que o tempo de trabalho requerido para a produção seja considerado por Marx como um fundamento essencial da economia, a partir do qual ele concebe a lei do valor, enunciada como,

\begin{abstract}
Independentemente do modo como estejam fixados ou regulados entre si os preços das diversas mercadorias, é a lei do valor que, num primeiro momento, rege seu movimento. Quando diminui o tempo de trabalho requerido para produzir essas mercadorias, os preços baixam; quando ele aumenta, os preços sobem, mantendo-se constantes as demais circunstâncias. (MARX, 2011, p. 211).
\end{abstract}

Coerentemente com a teoria de Marx, a determinação da curva de oferta de um produto em relação aos seus preços pode ser definida pelo tempo de trabalho para a sua produção. Na origem de tal curva encontra-se o custo total em tempo de trabalho necessário para a geração de um produto, de acordo com as condições em que ocorre. Uma curva de custo total em tempo de trabalho em condições heterogêneas de produção, considerando uma variação contínua das mesmas, é mostrada na figura 1.

Figura 1 - Custo total em tempo de trabalho em relação à quantidade produzida

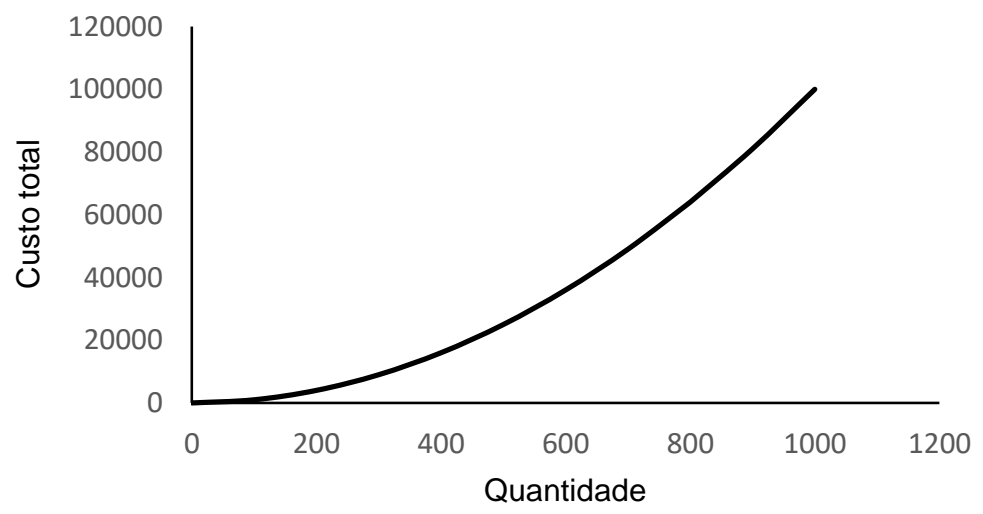

Como mostra a figura 1, para produzir uma quantidade (q), é necessário que o produtor com o maior custo receba uma remuneração proporcional ao tempo de 
trabalho aplicado. Esta remuneração é realizada pela atribuição de um preço ao produto. Assim, o determinante fundamental deste preço é o diferencial de tempo de trabalho por unidade de produto. Em termos matemáticos este diferencial é calculado pela derivada do custo total em relação a quantidade produzida. Assim, considerando o custo total mostrado na figura 1 como $\left(c_{t}\right)$ e o preço como $(p)$, temos

$$
\frac{d c_{t}}{d q}=c_{m g}=p
$$

A partir da curva mostrada na figura 1, obtém-se a curva da variação dos preços em relação à quantidade produzida (curva de oferta), a qual é mostrada na figura 2. Assim, considerando a curva de oferta como,

$$
p=f(q)
$$

A partir da expressão (8) pode-se calcular o custo total de produção que corresponde à área abaixo da curva mostrada na figura 2 como,

$$
c_{t}=\int_{0}^{q} p d q
$$

Figura 2 - Custo total em função da quantidade

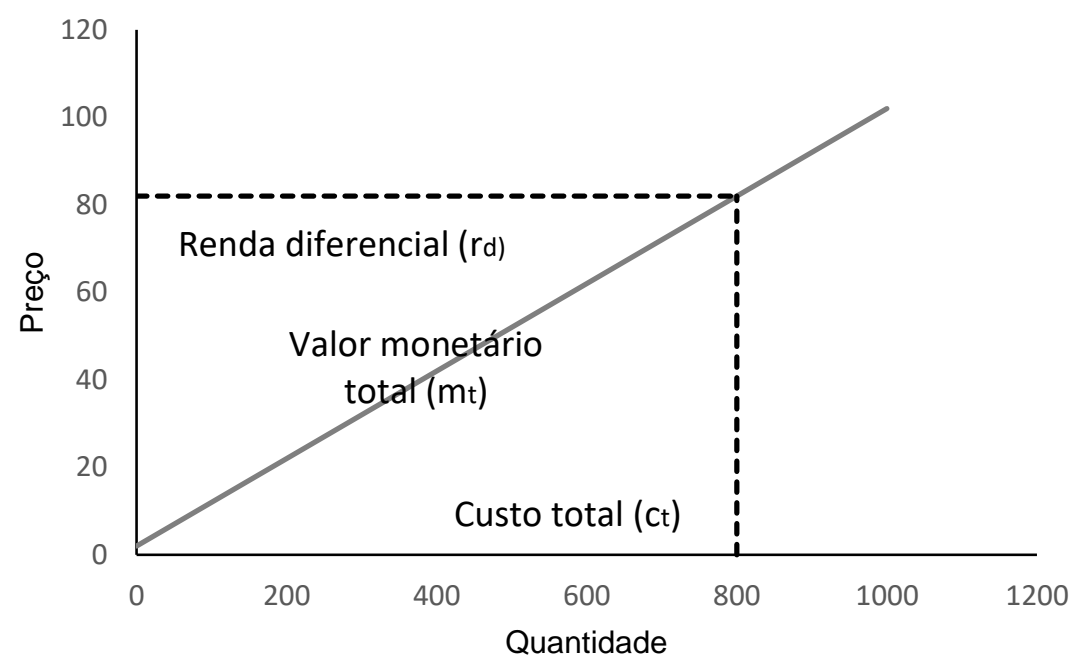

Como mostrado na curva de oferta representada na figura 2, o valor monetário total da produção $\left(m_{t}\right)$ é definido pela área do retângulo formado pela multiplicação do preço pela quantidade, ou seja,

$$
m_{t}=p_{p} q_{p}
$$

Neste caso, os produtores que possuem custos mais baixos obtêm uma renda diferencial $\left(r_{d}\right)$, correspondente à área acima da curva de oferta delimitada pelo preço, definida por, 


$$
r_{d}=\int_{0}^{q_{p}}\left(p_{p}-p\right) d q
$$

O que implica que o valor monetário total da produção $\left(m_{t}\right)$ é,

$$
m_{t}=c_{t}+r_{d}
$$

E o custo de produção total,

$$
C_{t}=m_{t}-r_{d}
$$

O valor monetário total $\left(\mathrm{m}_{\mathrm{t}}\right)$, portanto, difere do custo total $\left(\mathrm{c}_{\mathrm{t}}\right)$, na medida em que inclui as rendas diferenciais $\left(r_{d}\right)$. Assim, exceto em condições de produção homogêneas, que não geram rendas (neste caso a curva de preços é horizontal, pois estes são inelásticos em relação a quantidade produzida), o preço difere do valor médio em tempo de trabalho.

Evidentemente, o processo descrito acima é influenciado por outros como a equalização das taxas de lucro (MARX, 2017, p. 189). No entanto, sua efetividade é suficiente para assegurar a validade da lei do valor citada anteriormente (MARX, 2011, p. 211), na medida em que uma relação inversa entre tempo de trabalho e preços tem sido empiricamente observada em um grande número de trabalhos (COCKSHOTT, COTTRELL e MICHELSON, 1993; COCKSHOTT, 2011; ZACHARIAH, 2006).

As relações entre valores e preços discutida nos parágrafos anteriores pode ser formalizada por meio da programação linear, uma técnica desenvolvida no âmbito da álgebra linear que proporciona resultados coerentes com os do cálculo diferencial. Especialmente importante neste sentido é o fato de, a partir de um problema de programação linear, denominado primal, poder ser deduzido outro problema, denominado dual, que fornece os valores equivalentes ao das derivadas parciais da função a ser otimizada do problema primal em relação a cada uma das suas restrições. A modelagem por meio da programação linear, portanto, pode proporcionar uma análise da formação de um conjunto de preços que se condicionam mutuamente.

No modelo aqui proposto o problema primal fornece a quantidade de cada produto para consumo final e meio de produção a ser gerada em cada condição técnica que minimiza o trabalho socialmente necessário para a produção, sob restrições relativas à satisfação da demandada dos produtos de consumo final, às exigências de meios de produção e aos recursos naturais disponíveis. A partir deste problema primal obtém-se o problema dual que fornece os preços das mercadorias e dos meios de produção, assim como as rendas diferencias relacionadas a cada recurso natural, que maximizam o valor agregado monetário. $\mathrm{O}$ modelo considera como variáveis exógenas a demanda de produtos de consumo final, os excedentes de meios de produção e o acesso aos recursos naturais.

O problema primal do modelo é descrito como,

$$
\begin{gathered}
\text { Minimizar } \sum c_{i}^{l} q_{i}^{l}+\sum c_{z}^{x} k_{z}^{x} \\
\text { Sujeito às restrições } \\
\sum q_{i}^{l} \geq D_{i} \\
\sum k_{z}^{x}-\sum a_{\mathrm{iz}}^{l} q_{i}^{l} \geq K_{z} \\
\sum \sigma_{\mathrm{jz}}^{x} k_{z}^{x} \leq R_{j}
\end{gathered}
$$


Onde temos,

$c_{i}^{l}=$ quantidade $c$ de trabalho necessária por unidade do produto $i$ com a técnica $l$.

$q_{i}^{l}=$ quantidade $q$ do produto $i$ produzido com a técnica $l$.

$c_{z}^{x}=$ quantidade $c$ de trabalho necessário por unidade de meio de produção $z$ produto com a técnica $x$.

$k_{z}^{x}=$ quantidade $k$ do meio de produção $z$ (gerado pelo trabalho) com a técnica $x$.

$K_{z}=$ quantidade excedente $K$ do meio de produção $z$ necessária para assegurar 0 aumento da produção futura.

$a_{\mathrm{iz}}^{l}=$ quantidade $a$ do meio de produção $z$ necessária para a produção de uma unidade do produto $i$ com a técnica $l$.

$D_{i}=$ quantidade demandada $D$ do produto para consumo final $i$.

$\sigma_{\mathrm{jz}}^{x}=$ quantidade $\sigma$ do recurso natural $j$ necessário para a produção do meio de produção z com a técnica $x$.

$R_{j}=$ quantidade máxima $R$ a ser utilizada do recurso natural $j$.

A partir do problema primal descrito anteriormente é definido um problema dual, que fornece os preços dos produtos e as rendas relacionadas aos recursos naturais, o qual é formulado como,

$$
\begin{array}{r}
\text { Maximizar } \sum p_{i} D_{i}+\sum \beta_{z} K_{z}-\sum r_{j} R_{j} \\
\text { Sujeita à restrição } \\
p_{i}-\sum a_{\mathrm{iz}}^{l} \beta_{z} \leq c_{i}^{l} \\
\beta_{z}-\sum \sigma_{j z}^{x} r_{j} \leq c_{z}^{x}
\end{array}
$$

Onde, além das variáveis do problema primal, já descritas, temos,

$p_{i}=$ preço $p$ do produto $i$.

$\beta_{z}=$ preço $\beta$ do meio de produção $z$ (gerado pelo trabalho).

$r_{j}=$ preço $r$ do recurso natural $j$.

De acordo com o teorema da dualidade, com as soluções ótimas temos,

$$
\text { Mínimo } \sum c_{i}^{l} q_{i}^{l}+\sum c_{z}^{x} k_{z}^{x}=\text { Máximo } \sum p_{i} D_{i}+\sum \beta_{z} K_{z}-\sum r_{j} R_{j}
$$

Ou seja, o mínimo de trabalho socialmente necessário (valor em tempo de trabalho) corresponde ao máximo valor agregado monetário, consideradas as demandas dos produtos, as condições de produção, os excedentes de meios de produção e a disponibilidade de recursos naturais.

É importante salientar que os resultados fornecidos pelo problema dual do modelo não podem ser considerados como valores em tempo de trabalho (valorestrabalho). De fato, há modelos de programação linear, como o de Morishima (1973, p. 184-185), cujo problema primal minimiza o tempo de trabalho (como o apresentado neste artigo), nos quais o problema dual é empregado para calcular valores-trabalho. Porém, a consideração da escassez de recursos naturais nesses modelos faz, necessariamente, com que a solução dual não forneça valores-trabalho, como mostrado, por exemplo, por Hoffmann e Cunha (2009). Isto ocorre porque a consideração de recursos naturais escassos provoca o surgimento de rendas, as quais se incorporam nos demais valores fornecidos pela solução dual. Isto é demonstrado pelas expressões (19) e (20) e, de forma ainda mais clara, pela expressão (21). Observa-se que, no lado direito desta última expressão, o valor da renda gerada pela escassez dos recursos naturais deve ser subtraído dos valores totais dos produtos de consumo e dos meios de produção para a obtenção do valortrabalho total (mostrado lado no esquerdo da expressão (21)). Portanto, a 
consideração dos valores dos produtos finais e dos meios de produção fornecidos pela solução dual do modelo como valores-trabalho é errônea quando se considera a possibilidade de escassez de recursos naturais. Justifica-se, assim, que estes valores sejam considerados como os preços que seriam definidos excluindo outros processos que influenciam a sua formação (como a equalização das taxas de lucro), o que é necessário para que a equivalência entre o valor agregado e o tempo de trabalho socialmente necessário possa ser formalmente demonstrada de acordo com a teoria marxista do valor (SILVA NETO, 2020a).

Observa-se que a expressão (18) descreve que o valor total em tempo de trabalho é equivalente ao valor monetário total menos as rendas, o que corresponde ao que é descrito pela expressão (13). Isto demonstra que o modelo de programação linear descreve formalmente os determinantes da oferta tal como eles foram discutidos no início desta seção a partir do cálculo diferencial e integral. Neste sentido, no modelo os preços obtidos correspondem a valores marginais, na medida em que as variáveis do problema dual que expressam os preços correspondem à variação do valor da função objetivo do problema primal provocada pela variação dos coeficientes do lado direito das suas restrições.

A partir deste modelo é possível deduzir a equação adotada para o cálculo do valor agregado na ADSA. Isto é feito considerando que as expressões (19) e (20) descritas no problema dual, macroeconômico, de formação de preços, podem ser transformadas na equação empregada na ADSA para calcular o valor agregado nas unidades de produção, bastando para isto nelas considerar as quantidades do produto. Desta forma, considerando a expressão (19), o valor agregado pode ser calculado por meio da sua multiplicação pela quantidade produzida, ou seja,

$$
V A=Q c_{i}^{l}=Q p_{i}-Q \sum a_{\mathrm{iz}}^{l} \beta_{z}
$$

No conjunto da economia, a quantidade total dos meios de produção que requerem apenas um ciclo para serem consumidos deve ser novamente produzida, assim como a parte que foi consumida dos meios de produção que requerem mais de um ciclo de produção. Mas, em uma unidade de produção, evidentemente não é possível repor apenas uma parte dos meios de produção que requerem mais de um ciclo para serem consumidos. Assim, é necessário considerar a depreciação no ciclo sofrida por tais meios de produção. Quando a expressão (22) é considerada do ponto de vista microeconômico, portanto, os meios de produção devem ser repartidos entre os que são consumidos no ciclo, sendo denominado "consumo intermediário", e a uma "depreciação" dos que são consumidos em vários ciclos de produção, ou seja,

$$
Q \sum a_{\mathrm{iz}}^{l} \beta_{z}=C I+D
$$

E considerando que,

$$
Q p_{i}=P B
$$

Obtêm-se a expressão (4), a mesma que é empregada para o cálculo do valor agregado na ADSA (DUFUMIER, 1996, p. 95), como já mencionado.

$$
V A=P B-C I-D
$$

Isto completa a demonstração de que o valor agregado não é uma medida da riqueza produzida, mas apenas o equivalente monetário do tempo de trabalho socialmente necessário para gerá-la.

Normalmente, é ao proprietário dos meios de produção, ou a um agente econômico a ele subordinado, que cabe a gestão da unidade de produção. No entanto, o proprietário dos meios de produção não se apropria de todo o valor agregado. Ele 
deve dividir este valor agregado com outros agentes econômicos, cada qual recendo uma renda (a qual não deve ser confundida com a renda diferencial considerada na formação dos preços). A renda do proprietário dos meios de produção normalmente é calculada por (DUFUMIER, 1996, p. 95),

$$
\mathrm{R}=\mathrm{VA}-\mathrm{I}-\mathrm{J}-\mathrm{S}-\mathrm{T}
$$

Onde,

$\mathrm{R}$ = renda do proprietário dos meios de produção

$\mathrm{VA}=$ valor agregado.

$\mathrm{S}=$ salários pagos aos trabalhadores permanentes ou temporários.

I = impostos pagos ao Estado.

$\mathrm{J}=$ juros pagos aos bancos.

$\mathrm{T}$ = renda paga aos proprietários dos recursos naturais (como a terra, quando esta não pertence ao proprietário dos meios de produção gerados pelo trabalho).

No entanto, a expressão (25) não pode ser considerada consistente com a distribuição do valor agregado. Os impostos pagos ao Estado em muitos casos, rigorosamente, não fazem parte da distribuição do valor agregado mas correspondem ao pagamento de um valor que foi agregado fora da unidade de produção, tal como o consumo intermediário e a depreciação. Por exemplo, a construção e a manutenção de estradas, pontes e portos pelo Estado são atividades econômicas que agregam valor. A única diferença dessas atividades com as desenvolvidas pelo setor privado é que elas são pagas coletivamente ao poder público por meio de impostos e não diretamente aos proprietários privados das unidades de produção (HARRIBEY, 2009).

Outra inconsistência da expressão (25) com o cálculo do valor agregado diz respeito as rendas geradas pelos recursos naturais. Tais rendas se constituem em transferências de valor que existem justamente para assegurar a equivalência do valor agregado com o tempo de trabalho socialmente necessário. Assim, elas não se constituem em uma parte do valor agregado na unidade de produção, mas sim em uma transferência de valor entre as unidades de produção, gerada pela diferença de produtividade em uma atividade que depende diretamente da exploração de um recurso natural escasso.

As inconsistências apontadas na forma como normalmente é calculada a distribuição do valor agregado indica que, fundamentalmente, esta distribuição ocorre entre não proprietários e proprietários dos meios de produção. A renda dos proprietários dos meios de produção assim obtida é denominada lucro. Este lucro muitas vezes é dividido entre os proprietários dos meios de produção e os seus financiadores (como os Bancos), sendo neste último caso denominado juro.

Embora, como mencionado anteriormente, os impostos em muitos casos se constituem em um pagamento por um valor que foi agregado fora da unidade de produção, o seu montante normalmente não é proporcional a quantia por ela consumida de valor agregado pelas atividades realizadas pelo Estado (construção e manutenção de pontes e estradas, por exemplo), o que impossibilita calcular com precisão o valor agregado na unidade de produção. Esta dificuldade ocorre também em relação as rendas provocadas pela exploração de recursos naturais escassos. $O$ seu cálculo exigiria considerá-la não apenas quando ela é paga pelo uso de um recurso natural de outro proprietário, mas também quando o proprietário da unidade de produção se apropria de rendas diferenciais. Por estas razões, a expressão (25) pode ser considerada como uma forma aproximada de calcular a distribuição do valor agregado.

A demonstração realizada nesta seção deixa claro que o valor agregado, fundamentalmente, se constitui no equivalente monetário do tempo de trabalho socialmente necessário à produção. Neste sentido, tal demonstração corrobora a lei 
do valor de Marx (2011, p. 211), segundo a qual os preços são inversamente proporcionais à produtividade do trabalho. Assim, o aumento da produção de riquezas devido a um aumento da produtividade do trabalho no conjunto da economia, ao provocar a queda dos preços, pode manter inalterado o valor agregado. No entanto, como os preços incluem rendas, as unidades de produção que empregam diretamente recursos naturais escassos, diante de condições de produção heterogêneas, recebem uma porção maior do valor agregado social por meio de rendas diferenciais. Nas demais unidades de produção, as vantagens de um aumento da produtividade são apenas temporárias, na medida em que a generalização do aumento da produtividade (caso ela ocorra) leva ao ajuste do preço, restabelecendo a equivalência entre valor agregado e tempo de trabalho diretamente aplicado. Esses resultados serão ilustrados por meio do exemplo numérico apresentado na próxima seção.

\section{EXEMPLO NUMÉRICO}

O exemplo numérico discutido neste trabalho foi elaborado a partir de sistemas de cultura de milho do Noroeste do Rio Grande do Sul analisados por Silva Neto (2016). As características das culturas consideradas para a elaboração do modelo são apresentadas na tabela 1. Observa-se nesta tabela que o sistema 1 é o que proporciona a maior produtividade física e exige menos tempo de trabalho.

Tabela 1 - Características dos sistemas de cultura de milho considerados para a elaboração do modelo

\begin{tabular}{lcc}
\hline & Sistema 1 & Sistema 2 \\
\hline $\begin{array}{l}\text { Tempo de trabalho anual por superfície } \\
\text { (h/ha/ano) }\end{array}$ & 6 & 24 \\
Produção anual por superfície (t/ha/ano) & 10 & 6 \\
$\begin{array}{l}\text { Agrotóxicos por superfície por ano (I/ha/ano) } \\
\begin{array}{l}\text { Adubos químicos por superfície por ano } \\
\text { (t/ha/ano) }\end{array}\end{array}$ & 30 & 12 \\
$\begin{array}{l}\text { Combustíveis por superfície por ano (l/ha/ano) } \\
\text { Máquinas e equipamentos por superfície por }\end{array}$ & 100 & 0,15 \\
ano (unidades-trator/ha/ano) & 0,25 & 0,12 \\
\hline
\end{tabular}

Fonte: elaborado pelo autor a partir de dados de Silva Neto (2016)

Por outro lado, o sistema 1 é o que emprega mais insumos e equipamentos e, portanto, mais recursos naturais, representados neste exemplo pelo petróleo (os dados relativos à demanda de petróleo são meramente ilustrativos). Inversamente, o sistema 2 proporciona menor produtividade do trabalho, mas emprega menor quantidade de meios de produção e de petróleo. Salientamos que o uso de equipamentos foi considerado a partir da redução de todas as máquinas e implementos a unidades de trator, com o seu uso sendo representado pela renovação anual dos equipamentos por unidade de superfície (equivalente a depreciação nas unidades de produção), de acordo com a capacidade do parque de máquinas de cada sistema. 
Os coeficientes do modelo em unidades físicas por unidade do produto (tendo como referência a segunda linha da tabela 1 são mostrados na tabela 2.

Tabela 2 - Coeficientes do modelo (unidades por unidade de produto)

\begin{tabular}{lcccccc}
\hline & Sistema 1 & $\begin{array}{c}\text { Sistema } \\
2\end{array}$ & $\begin{array}{c}\text { Agrotó- } \\
\text { xicos }\end{array}$ & Adubos & $\begin{array}{c}\text { Combus- } \\
\text { tíveis }\end{array}$ & $\begin{array}{c}\text { Equipa- } \\
\text { mentos }\end{array}$ \\
\hline $\begin{array}{l}\text { Tempo de } \\
\text { trabalho }\end{array}$ & 0,6 & 4 & 1 & 0,5 & 0,3 & 50 \\
Agrotóxicos & 3 & 2 & & & & \\
Adubos & 0,04 & 0,025 & & & & \\
Combustíveis & 10 & 7,5 & & & & \\
$\begin{array}{l}\text { Equipamentos } \\
\text { Petróleo }\end{array}$ & 0,025 & 0,02 & & & & \\
Terra & 0,1 & 0,1667 & & 100 & 2 & \\
\hline Fonte: & & & & & &
\end{tabular}

Fonte: elaborado pelo autor

Como pode ser observado na tabela 2, o tempo de trabalho é inversamente proporcional aos meios de produção exigidos. Os coeficientes mostrados na tabela 2 foram utilizados para a formulação do problema primal do modelo, descrito abaixo,

Minimizar 0,6 $m 1+4 m 2+a g+0,5 a d+0,3 c+50 e$

Sujeito às restrições

demanda de milho) $\mathrm{m} 1+\mathrm{m} 2>=100$

demanda de agrotóxicos) $-3 \mathrm{~m} 1-2 \mathrm{~m} 2+\mathrm{ag}>=0$

demanda de adubos) $-0.04 \mathrm{~m} 1-0.025 \mathrm{~m} 2+\mathrm{ad}>=0$

demanda de combustíveis) $-10 \mathrm{~m} 1-7,5 \mathrm{~m} 2+\mathrm{c}>=0$

demanda de equipamentos) $-0,025 \mathrm{~m} 1-0,02 \mathrm{~m} 2+\mathrm{e}>=0$

disponibilidade de petróleo) $6 \mathrm{ag}+100 \mathrm{ad}+2 \mathrm{c}+200 \mathrm{e}<=4700$

disponibilidade de terra) $0,1 \mathrm{~m} 1+0,1667 \mathrm{~m} 2<=30$

Onde,

$\mathrm{m} 1=$ milho produzido pelo sistema 1

$\mathrm{m} 2$ = milho produzido pelo sistema 2

ag = agrotóxicos

$\mathrm{ad}=$ adubos químicos

$\mathrm{c}=$ combustíveis

$\mathrm{e}=$ equipamentos

$\mathrm{p}=$ petróleo

O problema dual do modelo é descrito como,

Maximizar $100 p m+0 p a g+0 p a d+0 p c+0 p e-4700 r p-30 r t$

Sujeito às restrições

m1) pm - 3 pag - 0,04 pad - 10 pc $-0,025$ pe $-0,1$ rt $<=0.6$

m2) pm - 2 pag $-0,025$ pad $-7,5$ pc $-0,02$ pe $-0,1667 \mathrm{rt}<=4$

ag) pag $-6 \mathrm{rp}<=1$

ad) pad - $100 \mathrm{rp}<=0.5$

c) pc -2 rp $<=0.3$

e) pe $-200 \mathrm{rp}<=50$ 
Onde,

pm = preço do milho

pag $=$ preço dos agrotóxicos

$\mathrm{pad}=$ preço dos adubos

$\mathrm{pc}=$ preço dos combustíveis

pe $=$ preço dos equipamentos

$\mathrm{rp}=$ renda do petróleo

$\mathrm{rt}=$ renda da terra

Os resultados obtidos com a solução do modelo são mostrados na tabela 3.

Tabela 3 - Resultados do modelo considerando uma disponibilidade de petróleo de 4.700 unidades por ciclo de produção (abundante)

\begin{tabular}{lcc}
\hline Variável & Quantidade & Preço ou renda \\
\hline Valor & 787 & 787 \\
Milho sistema 1 & 100 & 7,87 \\
Milho sistema 2 & 0 & \\
Agrotóxicos & 300 & 1,0 \\
Adubos & 4,0 & 0,5 \\
Combustíveis & 1.000 & 0,3 \\
Equipamentos & 2,5 & 50 \\
Petróleo & 4.700 & 0,0 \\
Terra & 10 & 0,0 \\
\hline
\end{tabular}

Fonte: elaborado pelo autor

Observa-se na tabela 3 que o valor em tempo de trabalho, fornecido pela solução do problema primal, é equivalente ao valor agregado, fornecido pela solução do problema dual. Além disto, observa-se na tabela 3 que toda a produção seria realizada pelo sistema 1 (único sistema da base ótima da solução), sendo que a renda gerada pelo petróleo e pela terra são nulas devido a estes recursos naturais serem abundante. O coeficiente correspondente a disponibilidade de terra foi fixado para que esta seja sempre abundante, o que explica que a exigência de terra mostrada na tabela 1 , de 10 hectares, seja bastante inferior à sua disponibilidade mostrada na expressão (33), de 30 hectares.

A tabela 4 mostra o cálculo dos resultados econômicos em cada atividade obtidos a partir de 8 horas de trabalho, considerando um salário fixo de 3 unidades monetárias. Como pode ser observado na tabela 40 milho gerado pelo sistema 2 proporciona um valor agregado menor do que as oito unidades de tempo aplicadas, o que indica que este sistema não é eficiente. Isto significa que se os agentes econômicos procurarem maximizar o valor agregado obtido na unidade de produção eles deveriam escolher o sistema 1. Por outro lado, é interessante observar, a partir dos resultados mostrados na tabela 4, que a taxa de lucro não seria um critério eficiente para a escolha do sistema de cultura, embora, em termos absolutos, o lucro seja um critério eficiente (pois, com o salário fixo, o lucro absoluto é diretamente proporcional ao valor agregado). 
Tabela 4 - Resultados econômicos obtidos pela aplicação de oito unidades de tempo de trabalho, com abundância de petróleo

\begin{tabular}{|c|c|c|c|c|c|c|}
\hline & $\begin{array}{l}\text { Sistema } \\
2\end{array}$ & $\begin{array}{c}\text { Sistema } \\
1\end{array}$ & $\begin{array}{l}\text { Agrotó- } \\
\text { xicos }\end{array}$ & Adubos & $\begin{array}{l}\text { Combus- } \\
\text { tíveis }\end{array}$ & $\begin{array}{l}\text { Equipa- } \\
\text { mentos }\end{array}$ \\
\hline Produção & 13,33 & 2,0 & 8,0 & 16 & 26,67 & 0,16 \\
\hline Valor da produção & 104,93 & 15,74 & 8,0 & 8,0 & 8,0 & 8,0 \\
\hline Agrotóxicos & 40 & 4,0 & & & & \\
\hline Valor dos agrotóxicos & 40 & 4,0 & & & & \\
\hline Adubos & 0,53 & 0,05 & & & & \\
\hline Valor dos adubos & 0,27 & 0,03 & & & & \\
\hline Combustíveis & 133,33 & 15 & & & & \\
\hline $\begin{array}{l}\text { Valor dos } \\
\text { combustíveis }\end{array}$ & 40 & 4,5 & & & & \\
\hline Equipamentos & 0,33 & 0,04 & & & & \\
\hline $\begin{array}{l}\text { Valor dos } \\
\text { equipamentos }\end{array}$ & 16,67 & 2,0 & & & & \\
\hline Renda rec. naturais & 0,0 & 0,0 & 0,0 & 0,0 & 0,0 & 0,0 \\
\hline Valor agregado & 8,0 & 5,22 & 8,0 & 8,0 & 8,0 & 8,0 \\
\hline Salário & 3,0 & 3,0 & 3,0 & 3,0 & 3,0 & 3,0 \\
\hline Lucro & 5 & 2,22 & & & & \\
\hline Taxa de lucro & $5,0 \%$ & $16,38 \%$ & $166,67 \%$ & $166,67 \%$ & $166,67 \%$ & $166,67 \%$ \\
\hline
\end{tabular}

Fonte: elaborado pelo autor

Consideraremos agora o caso em que a disponibilidade de petróleo diminui para 4.025 unidades físicas, tornando-o escasso. A tabela 5 mostra a solução do modelo neste caso.

Tabela 5 - Resultados do modelo considerando uma disponibilidade de 4025 unidades de petróleo por ciclo de produção (escasso)

\begin{tabular}{lcc}
\hline Variável & Quantidade & Preço ou renda \\
\hline Valor & 856,63 & 856,63 \\
Milho sistema 1 & 50 & 12,72 \\
Milho sistema 2 & 50 & \\
Agrotóxicos & 250 & 1,62 \\
Adubos & 3,25 & 10,81 \\
Combustíveis & 875 & 0,5063 \\
Equipamentos & 2,5 & 70,63 \\
Petróleo & 4.025 & 0,1031 \\
Terra & 13,335 & 0 \\
\hline
\end{tabular}

Fonte: elaborado pelo autor

Observa-se na tabela 5 que neste caso os dois sistemas devem ser empregados para satisfazer a demanda de 100 unidades de milho. Isto ocorre porque, com a escassez de petróleo, o sistema 1 deve ser em parte substituído pelo sistema 2 , que exige menos meios de produção e, assim, menos petróleo. Isto faz com que mais tempo de trabalho deva ser aplicado à produção, o que gera a renda do petróleo 
mostrada na tabela 5. Tal renda, ao ser incorporada aos preços dos meios de produção e, indiretamente, no do milho, assim como a maior exigência do sistema 2 em trabalho diretamente aplicado, faz com que os preços se elevem, como pode ser observado comparando-se os preços mostrados nas tabelas 3 e 5 .

Comparando as tabelas 3 e 5 observa-se que, enquanto a demanda e, portanto, a produção de milho se mantém inalterada, o valor agregado total (equivalente ao tempo de trabalho) passa de 787 para 856,63 unidades monetárias. Portanto, com a escassez de petróleo houve um aumento do valor agregado com a manutenção da riqueza gerada medida pela quantidade de produtos finais.

Na tabela 6 são mostrados os resultados econômicos obtidos pela aplicação de oito horas de trabalho, considerando uma disponibilidade de 4.025 unidades físicas de petróleo.

Tabela 6 - Resultados econômicos obtidos a partir da aplicação de oito horas de trabalho, com escassez de petróleo

\begin{tabular}{|c|c|c|c|c|c|c|}
\hline & $\begin{array}{c}\text { Sistema } \\
2\end{array}$ & $\begin{array}{c}\text { Sistema } \\
1\end{array}$ & $\begin{array}{c}\text { Agrotó- } \\
\text { xicos }\end{array}$ & Adubos & $\begin{array}{c}\text { Combus- } \\
\text { tíveis }\end{array}$ & $\begin{array}{l}\text { Equipa- } \\
\text { mentos }\end{array}$ \\
\hline Produção & 13,33 & 2,0 & 8,0 & 16 & 26,67 & 0,16 \\
\hline Valor da produção & 169,57 & 25,44 & 12,95 & 173,04 & 13,50 & 11,30 \\
\hline Agrotóxicos & 40 & 4,0 & & & & \\
\hline Valor dos agrotóxicos & 64,76 & 6,48 & & & & \\
\hline Adubos & 0,53 & 0,05 & & & & \\
\hline Valor dos adubos & 5,77 & 0,54 & & & & \\
\hline Combustíveis & 133,33 & 15,0 & & & & \\
\hline Valor dos combustíveis & 67,51 & 7,59 & & & & \\
\hline Equipamentos & 0,33 & 0,04 & & & & \\
\hline $\begin{array}{l}\text { Valor dos } \\
\text { equipamentos }\end{array}$ & 23,54 & 2,83 & & & & \\
\hline Renda do petróleo & & & 4,95 & 165,04 & 5,5 & 3,3 \\
\hline Renda da terra & 0,0 & 0,0 & & & & \\
\hline Valor agregado & 8,0 & 8,0 & 8,0 & 8,0 & 8,0 & 8,0 \\
\hline Salário & 3,0 & 3,0 & 3,0 & 3,0 & 3,0 & 3,0 \\
\hline Lucro & 5,0 & 5,0 & 5,0 & 5,0 & 5,0 & 5,0 \\
\hline Taxa de lucro & $3,04 \%$ & $24,47 \%$ & $166,67 \%$ & $166,67 \%$ & $166,67 \%$ & $166,67 \%$ \\
\hline
\end{tabular}

Observa-se na tabela 6 que agora os dois sistemas de cultura de milho geram um valor agregado equivalente ao número de horas de trabalho aplicadas. Como no caso anterior, o mesmo ocorre com os meios de produção. Na tabela 6 observa-se também que, apesar da produção de milho gerada pelo sistema 2 ser menor do que a proporcionada pelo sistema 1, o valor agregado por unidade de tempo de trabalho gerado é o mesmo para estes dois sistemas de cultura.

\section{VALOR AGREGADO E RIQUEZA NA ADSA}

O valor agregado desempenha um papel central na análise econômica de sistemas de produção realizadas no âmbito da ADSA. Neste método o cálculo do valor agregado é considerado como uma análise dos sistemas de produção efetuada a partir do interesse da sociedade, em contraste com o cálculo da renda, considerada como uma análise realizada a partir do interesse do agricultor. O caráter social do valor agregado é justificado também porque é pela sua repartição que diferentes 
agentes econômicos que contribuem para a produção são remunerados (DUFUMIER, 1996, p. 101).

No entanto, além disto, Dufumier (1996, p. 101) considera o valor agregado como uma medida da riqueza, como normalmente ocorre em trabalhos que empregam a ADSA. O principal problema decorrente desta consideração é que o valor agregado por unidade física de produto aumenta quando os produtos, simplesmente, tornam-se mais caros devido a um aumento do tempo de trabalho necessário para produzi-los. Como discutido anteriormente, isto pode ocorrer devido a um aumento da escassez de recursos naturais. Inversamente, o valor agregado por unidade de produto diminui a partir do aumento da produtividade do trabalho. Portanto, a identificação do valor agregado com produção de riqueza pode levar a que se subestime os efeitos de determinadas mudanças tecnológicas que, se generalizadas, podem diminuir a oferta de produtos agropecuários para a sociedade.

Para dar um exemplo desta situação, discutiremos brevemente o trabalho de Garambois e Devienne (2013) mencionado na introdução deste artigo. Neste trabalho, as autoras realizam um minucioso estudo da bovinocultura de leite da região francesa do Poitevin, observando uma capacidade maior de agregação de valor de sistemas baseados em pastagens e no uso de menos insumos e equipamentos em relação aos sistemas que empregam de forma intensiva silagem e alimentos concentrados, assim como quantidades mais elevadas de insumos e equipamentos. Por outro lado, as autoras detectaram uma diminuição de $10 \%$ do rendimento leiteiro por vaca nos sistemas baseados em pastagens e um aumento do rendimento leiteiro por vaca de $18 \%$ nos sistemas a base de silagem e concentrados entre 1990 e 2009 . A diminuição do rendimento leiteiro das vacas mantidas pelo sistema baseado em pastagens foi em boa parte compensada pelo aumento da área dedicada a produção de leite, ou seja, mais área passou a ser necessária para manter a produção. Assim, neste caso (como em geral na ADAS), a confusão entre valor agregado e riqueza leva a negligenciar o fato de que a promoção de sistemas de produção que geram mais valor agregado pode provocar uma diminuição da disponibilidade de alimentos, na medida em que a terra é um recurso escasso.

Evidentemente não se trata aqui de diminuir a importância dos resultados mostrados por Garambois e Devienne (2013). Em primeiro lugar devido aos efeitos sociais e ecológicos altamente benéficos constatados no estudo provocados pela adoção de sistemas de bovinocultura baseados em pastagens. Tais sistemas permitiram que muitos agricultores da região pudessem se manter na atividade, além de permitirem uma melhor conservação do solo e outros efeitos benéficos sobre o ambiente.

É interessante observar que, dada a possibilidade de possíveis diminuições da produção diante da importância de sistemas alternativos ao padrão tecnológico dominante para a promoção da sustentabilidade da agricultura, Silva Neto (2020b) propõe que estes sistemas sejam promovidos por meio de uma planificação ecológica, a qual permitiria uma avaliação mais objetiva dos seus efeitos sobre a sociedade. De acordo com o autor, tal avaliação, necessariamente de caráter interdisciplinar, poderia se constituir em um importante subsídio para um debate democrático visando a definição de um modelo agrícola ecologicamente sustentável e socialmente justo.

\section{CONCLUSÕES}

Os resultados obtidos neste trabalho permitem concluir que a promoção de sistemas de produção com alta capacidade de agregação de valor como forma de assegurar melhores condições para a reprodução social dos agricultores, como normalmente se observa nos estudos de ADSA, pode se mostrar contraditória com as 
necessidades da sociedade de produtos agropecuários, devido ao fato do aumento do valor agregado não implicar em aumento de riqueza.

Diante desta situação se coloca certo dilema. O problema é que, em âmbito local, é extremamente difícil encontrar alternativas que ampliem as possibilidades de reprodução social dos agricultores, especialmente os produtores familiares, que não impliquem no estímulo a atividades que agregam mais valor por superfície de terra. Esta situação é ainda mais evidente quando se trata de produtos orgânicos ou agroecológicos cujos preços são elevados, muitas vezes devido a demanda de consumidores de maior poder aquisitivo. Assim, entendemos que as contradições provocadas pela confusão entre valor agregado e riqueza analisadas neste artigo apontam para a necessidade de ampliar o debate para incluir propostas de caráter mais estrutural para o enfrentamento dos problemas provocados pelo padrão tecnológico dominante na agricultura (como as discutidas por SILVA NETO, 2020b).

Por outro lado, entendemos que os resultados apresentados neste artigo não devem ser interpretados no sentido de desestimular a promoção de sistemas de produção com maior capacidade de agregação de valor, especialmente quando se trata de ampliar as possibilidades de reprodução social de agricultores familiares. $O$ que alertamos é que tal agregação não pode ser considerada como produção de riqueza, o que indica a necessidade de medidas de caráter estrutural para assegurar, de forma mais ampla, as condições de reprodução social aos agricultores em maiores dificuldades.

Neste sentido, é importante ressaltar que os problemas aqui identificados decorrentes da consideração do valor agregado como equivalente à riqueza na ADSA não diminui a importância deste método para a promoção do desenvolvimento e a sustentabilidade da agricultura, na medida em que os seus procedimentos se baseiam em sólidos princípios teóricos e metodológicos (DUFUMIER, 1996). Ao contrário, os resultados obtidos neste artigo indicam que o tipo de conhecimento gerado por estudos baseados na ADSA é de grande importância para o estabelecimento de propostas de desenvolvimento e de promoção da sustentabilidade de forma coerente com a realidade agrária. Como mostra a estrutura do modelo apresentado, um conhecimento aprofundado dos aspectos técnicos e econômicos da agricultura é imprescindível para a análise da dinâmica da agricultura. E é justamente a análise desta dinâmica, realizada em boa parte a partir dos aspectos técnicos e econômicos dos sistemas de produção, que se constitui no principal objetivo da ADSA.

\section{REFERÊNCIAS}

BASSO, D; MÜENCHEN, J. V. Contribuição de diferentes tipos de empresas industriais para o desenvolvimento local: o caso do município de ljuí/RS. Desenvolvimento em Questão, ljuí: Ed. Unijuí, v. 4, n. 7, p. 95-125, 2006.

COCKSHOTT, P. Competing theories: Wrong or Not Even Wrong? Vlaams Marxistisch Tijdschrift, v. 45, n.2, p. 97-103, 2011.

COCKSHOTT P. W., COTTRELL, A.; MICHAELSON, G. J. Testing Labour Value Theory with input/output tables. Department of Computer Science, University of Strathclyde, 1993. Disponível em http://www.helmutdunkhase.de/marxts.pdf. Acesso em 25 dez. 2019

DEVIENNE, S.; GARAMBOIS, N.; DIEULOT, R.; LEBAHERS, G. Les systèmes de production économes et autonomes pour répondre aux enjeux agricoles 
d'aujourd'hui. Paris: Ministère de la Transition Écologique e Solidaire, Analyse Théma, décembre 2017.

DUFUMIER, M. Les projets de développement agricole. Manuel d'expertise. Éditions Karthala, Paris, 1996.

GARAMBOIS, N. ; DEVIENNE, S. Changement de paradigme et création de valeur ajoutée en agriculture : les cas de systèmes bovins hergabers economes du Bocage Poitevin. NESSE, n. 37, p. 33-49, jan./jui. 2013.

HARRIBEY, J.-M. Expectation, Financing and Payment of Nonmarket Production: Towards a New Political Economy. International Journal of Political Economy, $v$. 38, n.1, p. 32-52, Spring, 2009.

HARRIBEY, J.-M., La nature hors de prix. Ecorev, Revue critique d'écologie politique, n. 38, déc. 2011.

HARRIBEY, J.-M., La richesse, la valeur et l'inestimable. Fondements d'une critique socio-écologique de l'économie capitaliste. Paris: Les Liens qui Libèrent, 2013.

HARRIBEY, J.-M., Au coeur de la crise sociale et écologique du capitalisme: la contradiction entre richesse et valeur. Actuel Marx, n. 57, premier semestre 2015.

HOFFMANN, R.; CUNHA, M. S. da. Valores-Trabalho e Preços de Produção em Sistemas Econômicos Sraffianos com Terra Homogênea. RBE, v. 55, n.1, p. 53-76, 2001.

LUKÁCS, G. Para uma ontologia do ser social I. São Paulo: Boitempo, 2013.

MARX, K. O Capital, Livro I, Capítulo XX. São Paulo: Boitempo, 2011 [1867].

MARX, K. O Capital, Livro III, Capítulo XX. São Paulo: Boitempo, 2017 [1894].

MAZOYER, M. \& ROUDART, L. Histoire des Agricultures du Monde. Du Néolithique à la Crise Contemporaine. Paris:Éd. du Seuil, 1997.

MORISHIMA, M. Marx's Economics. A Dual Theory of Value and Growth. Cambridge: University Press, 1973.

SILVA NETO, B. Sistemas agrários e Agroecologia: a dinâmica da agricultura e as condições para uma transição agroecológica no município de Porto Xavier (RS). Rev. Bras. de Agroecologia, v.9, n.2, p. 15-29, 2014.

SILVA NETO, B. A Agroecologia na dinâmica do desenvolvimento rural de Cerro Largo (RS). Relatório técnico do Projeto de Extensão Chamada MCTI/MAPA/MDA/MEC/MPA/CNPq, n, 81, 2016. Disponível em http://beneweb.com.br/. Acesso em: 26 jul. 2020.

SILVA NETO, B. Com Marx, para além de Marx: ensaios sobre riquezas, valores e preços. Rio de Janeiro: Ed. Telha, 2020a. 
SILVA NETO, B. A planificação ecológica como um instrumento para promover de forma democrática e eficiente a sustentabilidade da agricultura. Extensão Rural, Santa Maria, v. 27, n. 1, p. 100-119, jan./mar. 2020b. Disponível em: https://doi.org/10.5902/2318179642985. Acesso em: 26 jul. 2020.

STOFFEL, J., A indústria da madeira e do mobiliado como uma alternativa para o desenvolvimento na região Noroeste Colonial do Rio Grande do Sul. 2004, 136f. Dissertação (Mestrado em Desenvolvimento) - Programa de Pós-Graduação em Desenvolvimento, Universidade Regional do Noroeste do Estado do Rio Grande do Sul, 2004.

ZACHARIAH, D. Labor value and equalization of profit rates: a multi-country study. Indian Development Review, v. 4, jun. 2006. 